\title{
Trends of variation of the laboratory parameters during the course of COVID-19 IIIness
}

\author{
Anjali Goyal ${ }^{1}$, Chandni Gadara ${ }^{2}$, Heta Patel ${ }^{3}$, Misha Antani ${ }^{4}$, Nilay Suthar ${ }^{5}$ \\ ${ }^{1}$ Associate Professor, ${ }^{2,3,4}$ Resident, Department of Pathology, ${ }^{5}$ Professor, Department of Medicine, Smt. NHL Municipal \\ Medical College, Ahmedabad, Gujarat, India
}

Background: The coronavirus pandemic which had its origin in the Wuhan China has been spreading across the globe with far reaching complications and a variable clinical course. A variation of the laboratory parameters during the disease course remains a constant parameter to monitor the disease course and progression. Since the laboratory parameters are standardized globally, these may also act as uniform guidelines for the patients monitoring and treatment. Aims and Objectives: The aim of the study was to serial charting of the laboratory parameters in the recovered and expired patients of COVID-19 and to determine an associated prognostic significance. Materials and Methods: A retrospective observational study from the laboratory and medical records was conducted on the patients admitted from March 17, 2020, to May 31, 2020, at the tertiary care center dedicated to the treatment of RT-PCR confirmed COVID-19 positive patients. Results: The group of parameters showing a poor prognosis include a rising WBC count, high neutrophilic percentage, low lymphocyte percentage $(<10)$ an NLR $>15$, low lymphocyte monocyte ratio $<3$, rising blood urea nitrogen, serum creatinine levels, and serum electrolyte levels. The liver function tests variation reflecting a poor metabolic activity of the liver, namely, a low serum albumin and albumin globulin ratio, rising SGOT levels, and total bilirubin levels. A highly significant variation in the acute phase reactants showing an exponential rise such as the serum lactate dehydrogenase levels, serum ferritin, fibrinogen, C-reactive protein, and IL 6 levels an increased level of D Dimer ( $>3$ ) and a prolongation of the APTT. Conclusion: The variation of the laboratory parameters acts as a fair marker for the disease progression. Since the disease shows a variable progression with a sudden worsening of the clinical symptoms, a comprehensive monitoring of the laboratory parameters serves to diagnose and treat the disease progression.

Key words: COVID-19; Laboratory parameters; Comparison
Access this article online

\section{Website:}

http://nepjol.info/index.php/AJMS DOI: $10.3126 / a j m s . v 12$ i12.39185

E-ISSN: 2091-0576

P-ISSN: 2467-9100

Copyright (c) 2021 Asian Journal of Medical Sciences

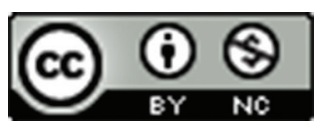

This work is licensed under a Creative Commons Attribution-NonCommercial 4.0 International License.

\section{INTRODUCTION}

The coronavirus pandemic has been spreading across the globe with far reaching complications and a variable clinical course. While the virus presents with varying clinical presentation with each wave, the variation of the laboratory parameters during the disease course helps to monitor the disease course and progression.

\section{Aims and Objectives}

1) To study the variation of the laboratory parameters from the hospital records of the patients admitted to a tertiary care hospital dedicated to the treatment of the patients with a Corona Virus infection as confirmed by a positive RT PCR test.

2) To analyze the variation of the laboratory parameters amongst the recovered $\&$ the expired patients. 


\section{MATERIALS AND METHODS}

A retrospective observational study from the laboratory and medical records was conducted on the patients admitted from March 17, 2020, to May 31, 2020, during the first wave of the disease, at the tertiary care center dedicated to the treatment of RT-PCR confirmed COVID-19 positive patients, after obtaining the institutional review board approval on June 10, 2020. Out of a total of 2739 patients admitted, consecutive 241 expired and 530 recovered patients were shortlisted of which 39 expired and 47 recovered patient's data were analyzed, after applying the inclusion and the exclusion criteria and their data. The statistical analysis was done using software SPSS 20.0 from IBM.

\section{Machines and reagents}

The routine blood tests and the biochemistry parameters and the acute phase reactants were carried out on the Siemens ADVIA - 2120, SIEMENS ADVIA 1800, Mindray BS- 200 and SIEMENS ADVIA Centaur XPT automated biochemistry analyzer, respectively.

\section{RESULTS}

The mean age of the patients was $62.62( \pm 14.42)$ and $37.83( \pm 14.71)$ years, with a M: F ratio of $4: 1$ and $2: 1$ in the expired and the recovered patients, respectively, (Table 1, Figure $1 \mathrm{a}$ and $\mathrm{b}$ ).

A progressive rise in the total WBC count and the neutrophil percentage, a decline in lymphocyte percentage and a lower monocytes percentage, along with a low lymphocyte monocyte ratio $(\mathrm{LMR}<3)$ and high neutrophil lymphocyte ratio (NLR $>3$ ) in the expired patients (Figure $2 \mathrm{a}$ ). An insignificant variation in the levels of hemoglobin, platelets, RDW, and hematocrit levels was seen (Figure 2b).

High blood urea nitrogen (BUN), serum creatinine levels, and serum electrolytes were seen in the expired patients with a significant variation (Figure 3).

Serum albumin globulin ratio, serum albumin levels, total serum protein, alkaline phosphatase, serum aspartate transaminase (AST), and the total bilirubin were high with a significant variation (Figure $4 \mathrm{a}$ and $\mathrm{b}$ ) while direct bilirubin,

\begin{tabular}{|c|c|c|c|c|}
\hline Parameters & Early & Middle & Late & P-value \\
\hline Total WBC & & & $>15000$ & $<0.00001$ \\
\hline Neutrophil \% & & & $>85$ & $<0.00001$ \\
\hline Monocytes\% & & & $<5$ & 0.006 \\
\hline Lymphocytes \% & & & $<10$ & $<0.00001$ \\
\hline LMR & & & $<2$ & $<0.00001$ \\
\hline NLR & & & $>15$ & $<0.00001$ \\
\hline RDW & & & $>15$ & 0.73 \\
\hline Hct & & & & 0.20 \\
\hline $\mathrm{Hb}$ & & & & 0.055 \\
\hline Platelets & & & & 0.98 \\
\hline BUN & & & $>110$ & $<0.00001$ \\
\hline Se Creatinine & & & $>2$ & $<0.00001$ \\
\hline Se Sodium & Constant & & & 0.007 \\
\hline Se Potassium & Constant & & & $<0.00001$ \\
\hline Se Chloride & & & & 0.96 \\
\hline Total Bilirubin & & & & 0.002 \\
\hline SGPT/ALT & $>80$ & & & 0.10 \\
\hline SGOT/AST & $>110$ & & & 0.043 \\
\hline Se Protein & & & $<5.7$ & 0.005 \\
\hline Alb:Glo ratio & & & $<1.5$ & $<0.00001$ \\
\hline Se Globulin & & & & 0.204 \\
\hline Indirect Bilirubin & & & & 0.209 \\
\hline Direct Bilirubin & & & $>0.3$ & 0.376 \\
\hline Se Alk & & & $>145$ & 0.002 \\
\hline \multicolumn{5}{|l|}{ Phosphatase } \\
\hline Se Albumin & & & $<3.1$ & 0.0001 \\
\hline IL6 & $>500$ & & & 0.33 \\
\hline Se Ferritin & & $>950(>3 \times)$ & & $<0.00001$ \\
\hline LDH & & & $>600(>3 \times)$ & 0.0001 \\
\hline CRP & & & $>55(>90 \times)$ & 0.027 \\
\hline Troponin C & $>20$ times & & & 0.085 \\
\hline D Dimer & $>3$ & & & 0.019 \\
\hline APTT & & $>50$ & & $<0.00001$ \\
\hline Fibrinogen & & & $>900(>2 \times)$ & $<0.00001$ \\
\hline
\end{tabular}




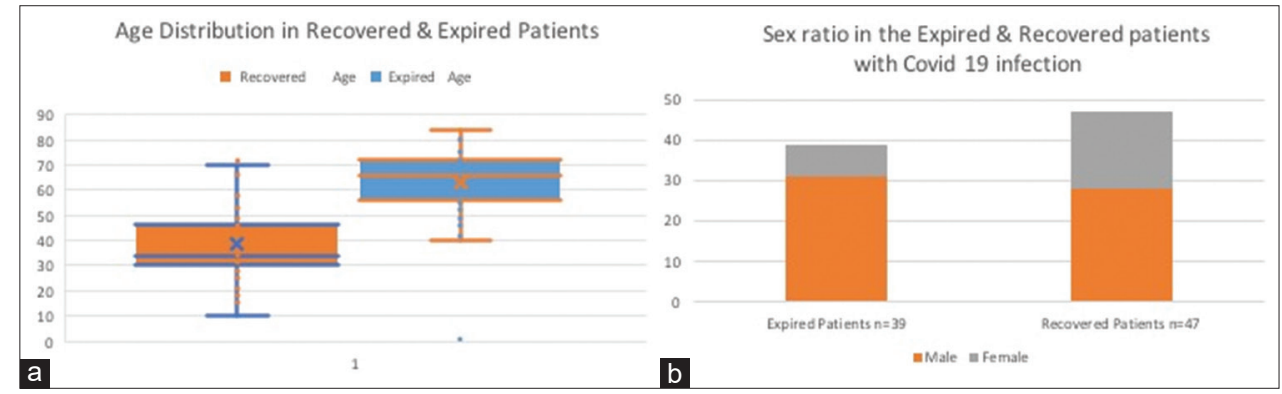

Figure 1: (a) The expired patients had a higher age distribution (median 66 years) compared Recovered patients (median 34 years). (b) The expired patients had a higher M:F sex ratio being 3.87:1 compared to 1.47:1 in the recovered patients

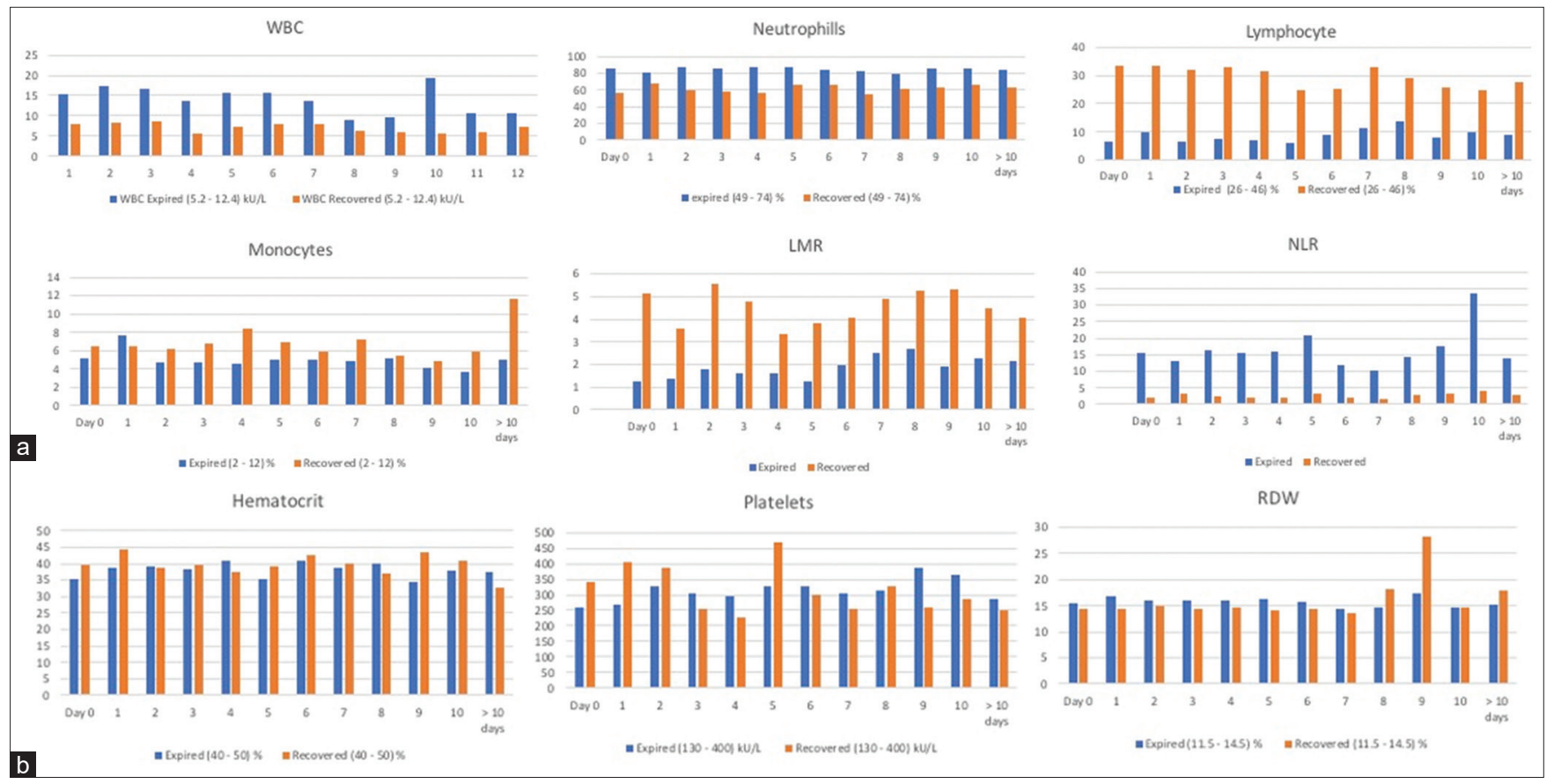

Figure 2: (a) A statistically significant variation was seen in the levels of total WBC, high neutrophil, low lymphocyte and lower monocytes levels with a significant variation in the LMR $(<3)$ and the NLR ratio and a lower Hemoglobin levels in the expired patients. (b) The hematocrit levels, platelet levels and the RDW show a statistically non-significant variation, although a low hematocrit and higher RDW was seen in the expired patient

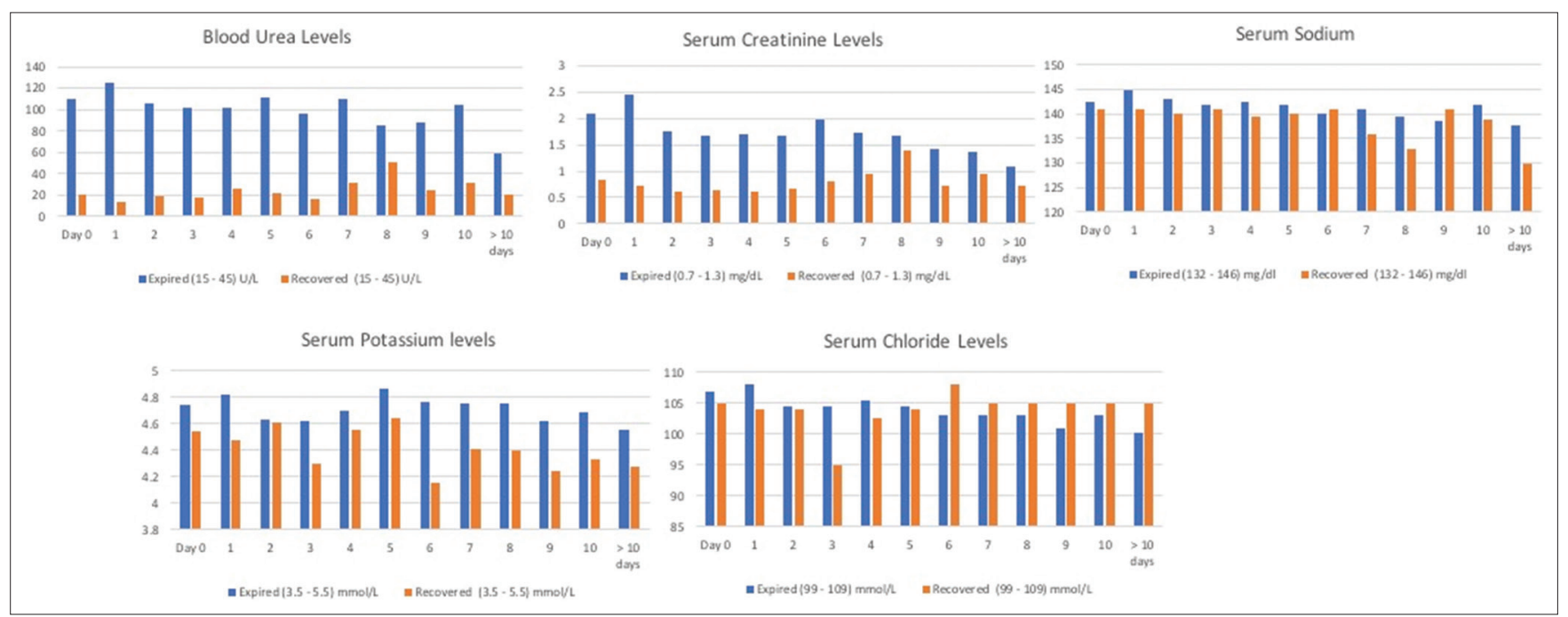

Figure 3: Renal function tests. The blood urea and serum creatinine levels and the serum electrolytes showed a statistically significant variation, with an increased level in the expired patients increasing more towards the terminal disease phase 
serum globulins, and serum alanine transaminase showed an insignificant variation.(Figure 4c).

Serum ferritin, lactate dehydrogenase (LDH), C-reactive protein (CRP), and serum fibrinogen levels showed a highly significant variation (Figure 5).

A highly significant variation was seen in the $\mathrm{D}$ dimer and APT'T levels (Figure 6).

\section{DISCUSSION}

The worldwide trend of age distribution pattern in COVID-19 positive patients ranges from a mean of $40-60$ years. ${ }^{1-3}$

An increased WBC count and neutrophils percentage along with a reduced lymphocyte and platelets counts in severe and fatal COVID-19 disease. ${ }^{2,45}$ A few studies reported a low WBC count in the disease. ${ }^{6-8}$

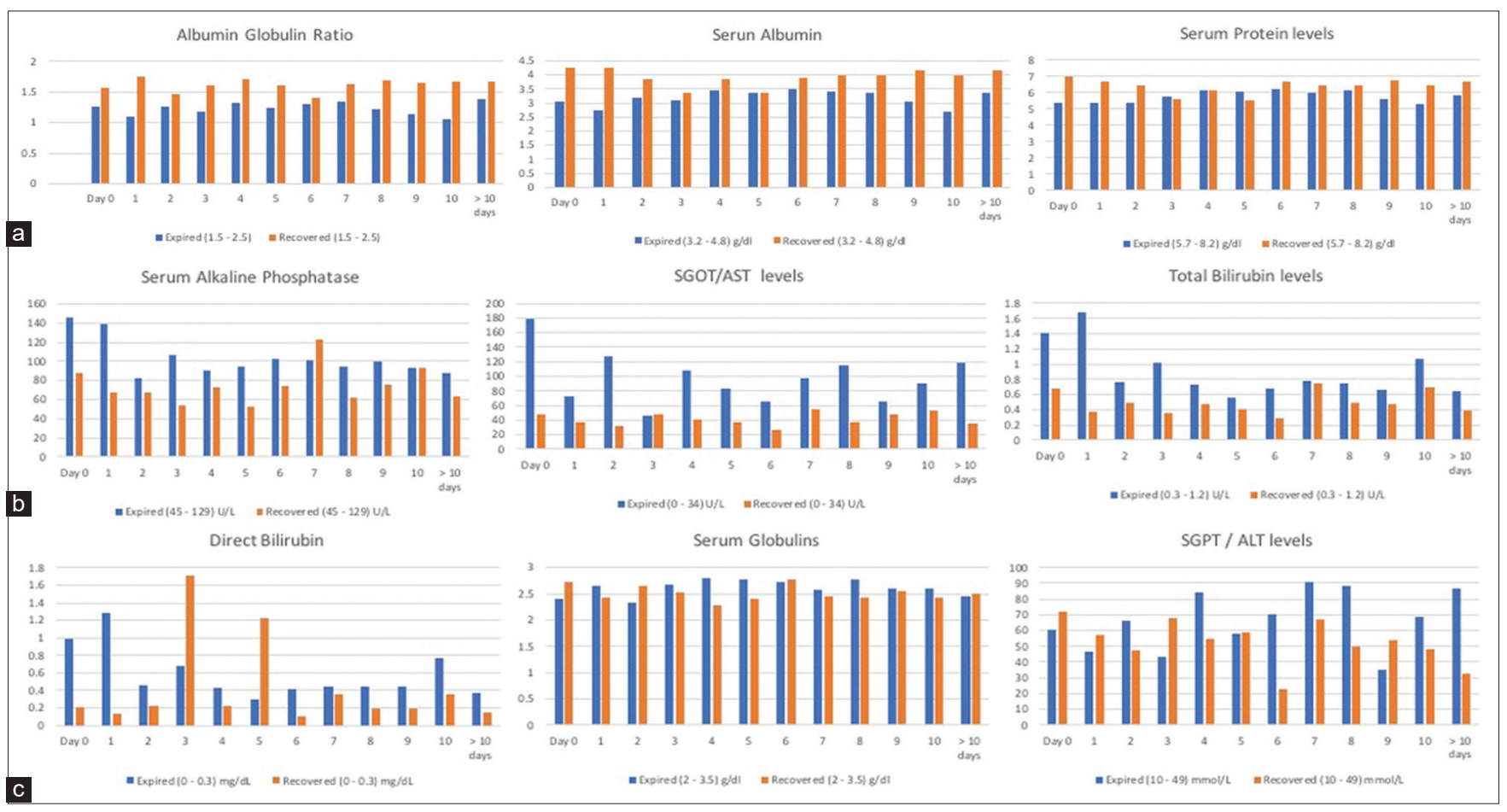

Figure 4: (a) A highly significant statistical variation was seen in the albumin globulin ratio, serum albumin levels and total protein levels, particularly in the imminent terminal disease phase in the expired patients. (b) The liver enzymes including the alkaline phosphatase and sgot along with the total bilirubin levels showed a significant statistical variation, with a consistently higher levels of the enzymes in the imminent terminal disease phase in the expired patients. (c) No significant statistical variation in the levels of Direct Bilirubin, Serum globulins and SGPT levels was seen

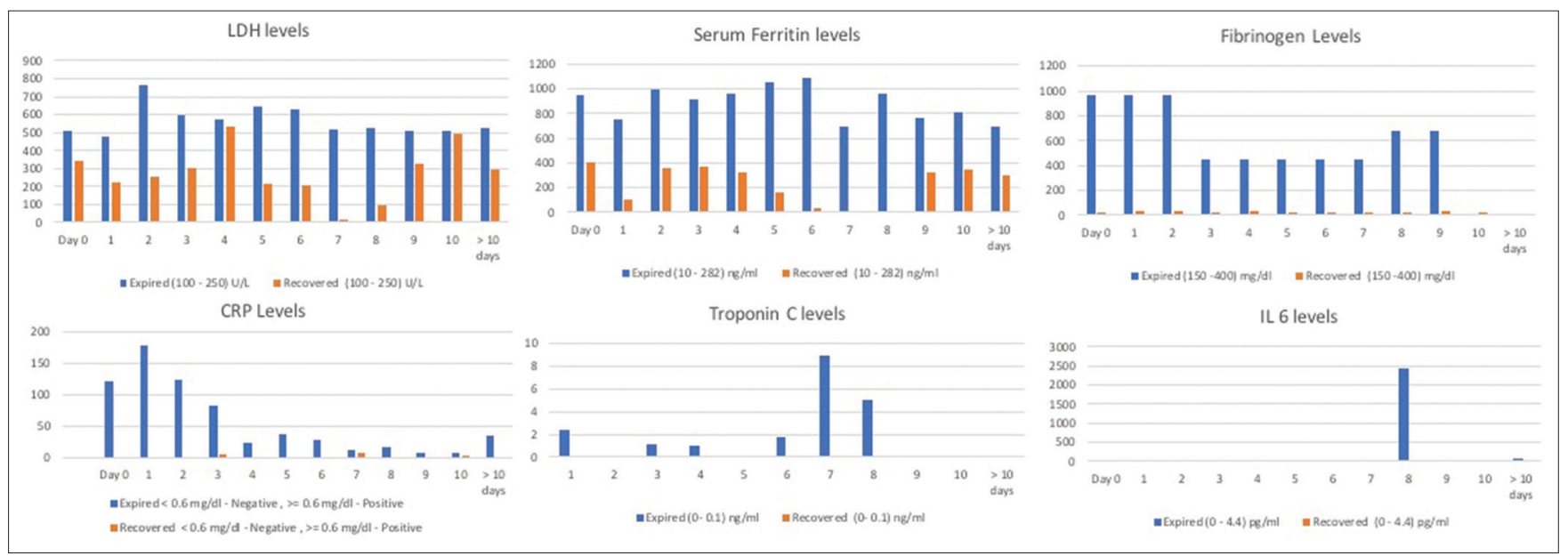

Figure 5: Variation of acute phase reactants. An exponential rise in the levels of serum LDH, serum ferritin, fibrinogen, CRP and IL6 levels was seen in the expired patients 


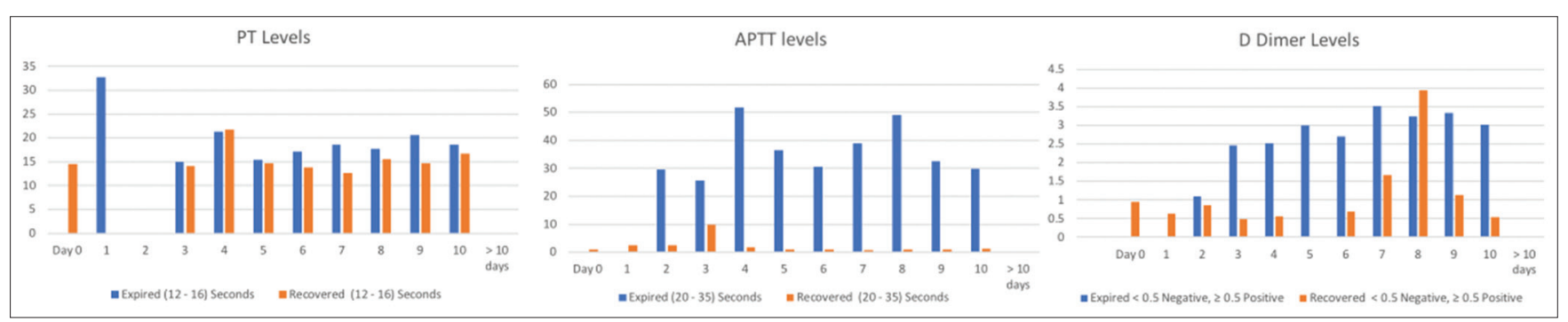

Figure 6: Variation in D-dimer levels and coagulation profile. A Dimer level of $>3$ was seen early in the disease in the expired patients, along with an increased value of APTT

Various studies observed a falling lymphocyte count with an increasing disease progression, ${ }^{9,10}$ more significantly a lymphocyte percentage of less than $5 \%$ was associated with a poor prognosis, ${ }^{11}$ along with a repletion of lymphocytes as an important factor for recovery. ${ }^{12}$

An expansion of monocyte population in the ICU bound patients was seen ${ }^{7}$ which differs from a low monocyte count observed in our study.

Although no studies comparing the variations in the values of RDW and hematocrit in COVID-19 patients were found, RDW variations during other viral diseases (liver failure in $\mathrm{HEV})^{13}$ and poor prognostic marker in various diseases was found. ${ }^{10-12}$

There was no significant variation in the platelet levels in various studies. ${ }^{1,13,14}$

Various studies indicate the importance of an acute renal damage and its association with mortality in COVID-19 particularly during the late disease course, ${ }^{15-21}$ whereas other studies showed a relatively low incidence of AKI in COVID-19.22,23

The liver enzymes were found to be altered in various studies, particularly in severe COVID-19 disease. ${ }^{24-28}$

A transient and mild variation of the liver function tests was mentioned in other studies with no significant relation to disease severity. ${ }^{29,30}$

A higher levels of the acute phase reactants were seen in more severe disease and in the expired patients than the survivors in a large number of studies. ${ }^{31-38}$ with a particular emphasis on the association of $\mathrm{LDH}$, and creatinine as the variables most predictive of respiratory failure, whereas maximal IL-6 level showed the strongest association with the need for mechanical ventilation, followed by maximal CRP level. ${ }^{11,38-41}$ An analysis of cardiac makers revealed a much higher indicated a higher fatality risk associated with abnormal myocardial parameters. $^{42}$

A higher threshold for $\mathrm{D}$-dimer was found to be associated with an increased risk of pulmonary embolism and other complications in COVID-19 patients. ${ }^{43-47}$

A high admission D-dimer levels, and increasing D-dimer trends associated with a significantly greater risk of allcause mortality were reported in various studies. ${ }^{44,48-51}$

\section{Limitations of the study}

The study was conducted on the patients admitted to the hospital in a relatively small cohort of patients. This might represent the variation of results in a selective patient population who have an access to the medical care.

\section{CONCLUSION}

We conclude that a highly significant variation was seen in hematology parameters, renal function tests, acute phase reactants, and the coagulation profile in the expired patients. The parameters showing a significant association with the disease progression include

1. Hematology profile with a high WBC count with rising NLR (>3), reduced LMR (<3) with falling lymphocyte percentage along with a borderline low hematocrit and high RDW

2. A significantly altered renal profile with rising BUN and serum creatinine levels

3. An alteration in the liver functions with lower albumin and total protein levels and rising liver enzymes and serum globulin levels

4. Rising levels of acute phase reactants including serum fibrinogen, CRP, and LDH along with an altered coagulation profile with rising D Dimer levels.

Since the disease shows a variable progression with a sudden worsening of the clinical symptoms, a comprehensive monitoring of the laboratory parameters serves to diagnose and treat the disease progression. 


\section{ACKNOWLEDGMENTS}

Dr. Shah CK; Professor and Head of Department of pathology. Dr. Hemant Tiwari; Statistician: Department of Preventive and Social Medicine (PhD Statistics). Mr. Manpreet Singh; IT and Records SVP Hospital (Affiliated to NHL Medical College).

\section{REFERENCES}

1. Mardani R, Vasmehjani AA, Zali F, Gholami A, Nasab SD, Kaghazian $\mathrm{H}$, et al. Laboratory parameters in detection of COVID-19 patients with positive RT-PCR; a diagnostic accuracy study. Arch Acad Emerg Med. 2020;8(1):e43.

2. Zhang B, Zhang J, Chen H, Chen L, Chen Q, Li M, et al. Novel Coronavirus disease 2019 (COVID-19): Relationship between chest CT scores and laboratory parameters. Eur J Nucl Med Mol Imaging. 2020;47(9):2083-2089.

https://doi.org/10.1007/s00259-020-04854-3

3. Zhang G, Zhang J, Wang B, Zhu X, Wang Q and Qiu S. Analysis of clinical characteristics and laboratory findings of 95 cases of 2019 novel coronavirus pneumonia in Wuhan, China: A retrospective analysis. Respir Res. 2020;21(1):74.

https://doi.org/10.21203/rs.3.rs-17712/v1

4. Henry BM, de Oliveira MH, Benoit S, Plebani M and Lippi G. Hematologic, biochemical and immune biomarker abnormalities associated with severe illness and mortality in Coronavirus disease 2019 (COVID-19): A meta-analysis. Clin Chem Lab Med. 2020;58(7):1021-1028.

https://doi.org/10.1515/cclm-2020-0369

5. Fan BE, Chong VC, Chan SS, Lim GH, Lim KG, Tan GB, et al. Hematologic parameters in patients with COVID-19 infection. Am J Hematol. 2020;95(6):E131-E134.

6. Huang C, Wang Y, Li X, Ren L, Zhao J, Hu Y, et al. Clinical features of patients infected with 2019 novel Coronavirus in Wuhan, China. Lancet. 2020;395(10223):497-506.

https://doi.org/10.1016/s0140-6736(20)30183-5

7. Gao Y, Li T, Han M, Li X, Wu D, Xu Y, et al. Diagnostic utility of clinical laboratory data determinations for patients with the severe COVID-19. J Med Virol. 2020;92(7):791-796.

https://doi.org/10.1002/jmv.25770

8. Ferrari D, Motta A, Strollo M, Banfi G and Locatelli M. Routine blood tests as a potential diagnostic tool for COVID-19. Clin Chem Lab Med. 2020;58(7):1095-1099.

https://doi.org/10.1515/cclm-2020-0398

9. Tan L, Wang $Q$, Zhang $D$, Ding J, Huang $Q$, Tang $Q$, et al. Lymphopenia predicts disease severity of COVID-19: A descriptive and predictive study. Signal Transduct Target Ther. 2020;5(1):33.

https://doi.org/10.1038/s41392-020-0159-1

10. Hammons L, Filopei J, Steiger D and Bondarsky E. A narrative review of red blood cell distribution width as a marker for pulmonary embolism. J Thromb Thrombolysis. 2019;48(4):638-647.

https://doi.org/10.1007/s11239-019-01906-w

11. Salvagno GL, Sanchis-Gomar F, Picanza A and Lippi G. Red blood cell distribution width: A simple parameter with multiple clinical applications. Crit Rev Clin Lab Sci. 2015;52(2):86-105. https://doi.org/10.3109/10408363.2014.992064

12. Fava C, Cattazzo F, Hu ZD, Lippi G and Montagnana M. The role of red blood cell distribution width (RDW) in cardiovascular risk assessment: Useful or hype? Ann Transl Med. 2019;7(20):581. https://doi.org/10.21037/atm.2019.09.58

13. Wu J, Zhang X, Liu H, Guo N, Pan Q and Wang Y. RDW, NLR and $R L R$ in predicting liver failure and prognosis in patients with hepatitis E Virus infection. Clin Biochem. 2019;63:24-31. https://doi.org/10.1016/j.clinbiochem.2018.11.012

14. Li LQ, Huang T, Wang YQ, Wang ZP, Liang $Y$, Huang TB, et al. COVID-19 patients' clinical characteristics, discharge rate, and fatality rate of meta-analysis. J Med Virol. 2020;92(6):577-583. https://doi.org/10.1002/jmv.25757

15. Liu $Y, Q i F Y$, Wei $L$ and Cheng $Q L$. Clinical analysis of kidney injury in patients with COVID-19. Zhonghua Yi Xue Za Zhi. 2020;100(26):2028-2031.

16. Gabarre P, Dumas G, Dupont T, Darmon M, Azoulay E and Zafrani L. Acute kidney injury in critically ill patients with COVID-19. Intensive Care Med. 2020;46(7):1339-1348. https://doi.org/10.1007/s00134-020-06153-9

17. Pelayo J, Lo KB, Bhargav R, Gul F, Peterson E, DeJoy lii R, et al. Clinical characteristics and outcomes of communityand hospital-acquired acute kidney injury with COVID-19 in a US Inner City Hospital system. Cardiorenal Med. 2020;10(4):223-231.

https://doi.org/10.1159/000509182

18. Cheng $\mathrm{Y}$, Luo R, Wang $\mathrm{K}$, Zhang M, Wang Z, Dong L, et al. Kidney disease is associated with in-hospital death of patients with COVID-19. Kidney Int. 2020;97(5):829-838. https://doi.org/10.1016/j.kint.2020.03.005

19. Pei G, Zhang Z, Peng J, Liu L, Zhang C, Yu C, et al. Renal involvement and early prognosis in patients with COVID-19 pneumonia. J Am Soc Nephrol. 2020;31(6):1157-1165. https://doi.org/10.1681/asn.2020030276

20. Xia P, Wen Y, Duan Y, Su H, Cao W, Xiao M, etal. Clinicopathological features and outcomes of acute kidney injury in critically ill COVID-19 with prolonged disease course: A retrospective cohort. J Am Soc Nephrol. 2020;31(9):2205-2221. https://doi.org/10.1681/asn.2020040426

21. Cheng A, Hu L, Wang Y, Huang L, Zhao L, Zhang C, et al. Diagnostic performance of initial blood urea nitrogen combined with D-dimer levels for predicting in-hospital mortality in COVID-19 patients. Int J Antimicrob Agents. 2020;56(3):106110. https://doi.org/10.1016/j.ijantimicag.2020.106110

22. Na KR, Kim HR, Ham Y, Choi DE, Lee KW, Moon JY, et al. Acute kidney injury and kidney damage in COVID-19 patients. J Korean Med Sci. 2020;35(28):e257. https://doi.org/10.3346/jkms.2020.35.e257

23. Wang L, Li X, Chen H, Yan S, Li D, Li Y, et al. Coronavirus disease 19 infection does not result in acute kidney injury: An analysis of 116 hospitalized patients from Wuhan, China. Am J Nephrol. 2020;51(5):343-348. https://doi.org/10.1159/000507471

24. Wong YJ, Tan M, Zheng Q, Li JW, Kumar R, Fock KM, et al. A systematic review and meta-analysis of the COVID-19 associated liver injury. Ann Hepatol. 2020;19(6):627-634. https://doi.org/10.1016/j.aohep.2020.08.064

25. Bertolini A, van de Peppel IP, Bodewes FA, Moshage H, Fantin A, Farinati $F$, et al. Abnormal liver function tests in patients with COVID-19: Relevance and potential pathogenesis. Hepatology. 2020;72(5):1864-1872. https://doi.org/10.1002/hep.31480

26. Kumar MP, Mishra S, Jha DK, Shukla J, Choudhury A, Mohindra R, et al. Coronavirus disease (COVID-19) and the 
liver: A comprehensive systematic review and meta-analysis. Hepatol Int. 2020;14(5):711-722.

https://doi.org/10.1007/s12072-020-10071-9

27. Wijarnpreecha $K$, Ungprasert $P$, Panjawatanan $P$, Harnois DM, Zaver HB, Ahmed A, et al. COVID-19 and liver injury: A metaanalysis. Eur J Gastroenterol Hepatol. 2020;33(7):990-995. https://doi.org/10.1097/meg.0000000000001817

28. Boregowda U, Aloysius MM, Perisetti A, Gajendran M, Bansal P and Goyal $H$. Serum activity of liver enzymes is associated with higher mortality in COVID-19: A systematic review and metaanalysis. Front Med (Lausanne). 2020;7:431.

https://doi.org/10.3389/fmed.2020.00431

29. Garrido I, Liberal R and Macedo G. Review article: COVID-19 and liver disease-what we know on $1^{\text {st }}$ May 2020. Aliment Pharmacol Ther. 2020;52(2):267-275

https://doi.org/10.1111/apt.15813

30. Piano S, Dalbeni A, Vettore E, Benfaremo D, Mattioli M, Gambino CG, et al. Abnormal liver function tests predict transfer to intensive care unit and death in COVID-19. Liver Int. 2020;40(10):2394-2406.

https://doi.org/10.1111/liv.14565

31. Ji P, Zhu J, Zhong Z, Li H, Pang J, Li B, et al. Association of elevated inflammatory markers and severe COVID-19: A metaanalysis. Medicine (Baltimore). 2020;99(47):e23315. https://doi.org/10.1097/md.0000000000023315

32. Chen M, Wu Y, Jia W, Yin M, Hu Z, Wang R, et al. The predictive value of serum amyloid $A$ and $C$-reactive protein levels for the severity of Coronavirus disease 2019. Am J Transl Res. 2020;12(8):4569-4575

33. Ghayda RA, Lee J, Lee JY, Kim DK, Lee KH, Hong SH, et al. Correlations of clinical and laboratory characteristics of COVID-19: A systematic review and meta-analysis. Int J Environ Res Public Health. 2020;17(14):5026.

https://doi.org/10.3390/ijerph17145026

34. Soraya GV and Ulhaq ZS. Crucial laboratory parameters in COVID-19 diagnosis and prognosis: An updated meta-analysis. Med Clin (Barc). 2020;155(4):143-151. https://doi.org/10.1016/j.medcli.2020.05.017

35. Kiss S, Gede N, Hegyi P, Németh D, Földi M, Dembrovszky F et al. Early changes in laboratory parameters are predictors of mortality and ICU admission in patients with COVID-19: A systematic review and meta-analysis. Med Microbiol Immunol. 2021;210(1):33-47. https://doi.org/10.1007/s00430-020-00696-w

36. Henry BM, Aggarwal G, Wong J, Benoit S, Vikse J, Plebani M, et al. Lactate dehydrogenase levels predict Coronavirus disease 2019 (COVID-19) severity and mortality: A pooled analysis. Am J Emerg Med. 2020;38(9):1722-1726. https://doi.org/10.1016/j.ajem.2020.05.073

37. Tjendra Y, Al Mana AF, Espejo AP, Akgun Y, Millan NC, GomezFernandez $C$, et al. Predicting disease severity and outcome in COVID-19 patients: A review of multiple biomarkers. Arch Pathol Lab Med. 2020;144(12):1465-1474. https://doi.org/10.5858/arpa.2020-0471-sa

38. Liu F, Li L, Xu M, Wu J, Luo D, Zhu Y, et al. Prognostic value of interleukin-6, C-reactive protein, and procalcitonin in patients with COVID-19. J Clin Virol. 2020;127:104370.

39. Herold T, Jurinovic V, Arnreich C, Hellmuth JC, von BergweltBaildon M, Klein M, et al. Level of IL-6 predicts respiratory failure in hospitalized symptomatic COVID-19 patients. medRxiv. 10.1101/2020.04.01.20047381 Accessed April 27, 2020.

40. Keddie S, Ziff O, Chou MK, Taylor RL, Heslegrave A, Garr E, et al. Laboratory biomarkers associated with COVID-19 severity and management. Clin Immunol. 2020;221:108614. https://doi.org/10.1016/j.clim.2020.108614

41. Liu T, Zhang J, Yang Y, Ma H, Li Z, Zhang J, et al. The role of interleukin- 6 in monitoring severe case of Coronavirus disease 2019. EMBO Mol Med. 2020;12(7):e12421.

https://doi.org/10.15252/emmm.202012421

42. Han H, Xie L, Liu R, Yang J, Liu F, Wu K, et al. Analysis of heart injury laboratory parameters in 273 COVID-19 patients in one hospital in Wuhan, China. J Med Virol. 2020;92(7):819-823. https://doi.org/10.1002/jmv.25809

43. Ventura-Díaz S, Quintana-Pérez JV, Gil-Boronat A, Herrero-Huertas M, Gorospe-Sarasúa L, Montilla J, et al. A higher D-dimer threshold for predicting pulmonary embolism in patients with COVID-19: A retrospective study. Emerg Radiol. 2020;27(6):679-689. https://doi.org/10.1007/s10140-020-01859-1

44. Naymagon L, Zubizarreta N, Feld J, van Gerwen M, Alsen M, Thibaud S, et al. Admission D-dimer levels, D-dimer trends, and outcomes in COVID-19. Thromb Res. 2020;196:99-105. https://doi.org/10.1016/j.thromres.2020.08.032

45. Vidali S, Morosetti D, Cossu E, Luisi MLE, Pancani S, Semeraro $\mathrm{V}$, et al. D-dimer as an indicator of prognosis in SARS-CoV-2 infection: A systematic review. ERJ Open Res. 2020;6(2):00260-2020. https://doi.org/10.1183/23120541.00260-2020

46. Garcia-Olivé I, Sintes H, Radua J, Abad Capa J and Rosell A. D-dimer in patients infected with COVID-19 and suspected pulmonary embolism. Respir Med. 2020;169:106023. https://doi.org/10.1016/j.rmed.2020.106023

47. Li C, Hu B, Zhang Z, Qin W, Zhu Z, Zhai Z, et al. D-dimer triage for COVID-19. Acad Emerg Med. 2020;27(7):612-613.

48. Long $\mathrm{H}$, Nie L, Xiang $\mathrm{X}$, Li H, Zhang $\mathrm{X}$, Fu X, et al. D-Dimer and prothrombin time are the significant indicators of severe COVID-19 and poor prognosis. Biomed Res Int. 2020;2020:6159720.

https://doi.org/10.1155/2020/6159720

49. Yao Y, Cao J, Wang Q, Shi Q, Liu K, Luo Z, et al. D-Dimer as a biomarker for disease severity and mortality in COVID-19 patients: A case control study. J Intensive Care. 2020;8(1):49. https://doi.org/10.1186/s40560-020-00466-Z

50. Zhang L, Yan X, Fan Q, Liu H, Liu X, Liu Z, et al. D-dimer levels on admission to predict in-hospital mortality in patients with COVID-19. J Thromb Haemost. 2020;18(6):1324-1329. https://doi.org/10.1111/jth.14859

51. Simadibrata DM and Lubis AM. D-Dimer levels on admission and all-cause mortality risk in COVID-19 patients: A meta-analysis. Epidemiol Infect. 2020;148:e202. https://doi.org/10.1017/s0950268820002022 


\section{Authors Contribution:}

AG- Concept and Design, Intellectual Content, Literature search, Data Acquisition, Data Analysis, Statistical Analysis, Manuscript Preparation and Drafting,

Manuscript Approval, Guarantor; CG- Intellectual Content, Literature search, Data Acquisition, Data Analysis, Statistical Analysis; HP- Intellectual Content,

Literature search, Data Acquisition, Data Analysis, Statistical Analysis MA- Intellectual Content, Literature search, Data Acquisition, Data Analysis, Statistical Analysis NS- Manuscript Preparation and Drafting, Intellectual Content.

\section{Work attributed to:}

Smt. NHL Municipal Medical College, Ahmedabad 380 006, Gujarat, India

\section{Orcid ID:}

Dr. Anjali Goyal - (1) https://orcid.org/0000-0002-1945-0322

Dr. Chandni Gadara - (1) https://orcid.org/0000-0003-2159-8905

Dr. Heta Patel - (i) https://orcid.org/0000-0001-8595-2323

Dr. Misha Antani - (i) https://orcid.org/0000-0002-8260-4611

Dr. Nilay Suthar - (1) https://orcid.org/0000-0002-6425-7265

Source of Funding: None, Conflicts of Interest: None. 